\title{
Innovative business development: identifying and supporting future radical innovators
}

\author{
Sina Schmidt ${ }^{1}$ (i) . Dietrich von der Oelsnitz ${ }^{2}$
}

Received: 23 September 2019 / Accepted: 18 April 2020 / Published online: 6 May 2020

(c) The Author(s) 2020

\begin{abstract}
As the corporate environment becomes more volatile, uncertain, complex and ambiguous, companies are challenged to simultaneously adapt to multiple scenarios, develop radical innovations and destroy past successes. This flexible, i.e. agile and user-oriented, exploration must be ensured by exploiting already established efficiencies ("ambidextry"). However, most German SMEs do not engage in both radical and evolutionary innovations. Therefore, they tend to be disrupted. By investigating existing models regarding vuca-resilience and the development of radical innovations it was found that no practical guideline exists that provides established companies with VUCA-foresight in order to collaborate with radical innovators and thus achieve ambidextry. In order to close that gap, experts of five German companies were interviewed regarding their company's innovation behaviour. Based on the interviews as well as scientific approaches regarding VUCA-resilience and the development of radical innovations a ten-step guideline has been derived. The success of the model has been proofed by three German SMEs that initially pushed little or no radical innovation and subsequently even founded their own company builders. Since this paper only shows the ideal way for established companies to achieve ambidextry with the help of radical innovators, further research is needed to provide solutions for non-ideal cases. Additional validation can be achieved in which the model is not only validated by German SMEs, but also by companies of other sizes and countries.
\end{abstract}

Keywords Design driven innovation $\cdot$ Lab $\cdot$ Lean startup $\cdot$ Radical business model innovation $\cdot$ Scenarios $\cdot$ Spin-offs

\section{Introduction}

"Having spent forty years forecasting, I believe that the future world will be more volatile, more uncertain, more complex, and more ambiguous, or so it will seem if you are in a seat of leadership." (Johansen 2012).

The views and information expressed in this contribution are solely those of the authors and do not necessarily represent those of MHP Management-und IT-Beratung GmbH and its employees.

Sina Schmidt

sina.schmidt@mhp.com

Dietrich von der Oelsnitz

d.oelsnitz@tu-braunschweig.de

1 MHP Management-und IT-Beratung GmbH, Major-Hirst-Straße 3, 38442 Wolfsburg, Germany

2 Technische Universität Braunschweig, Institut für Unternehmensführung, Lehrstuhl für Organisation und Führung, Abt-Jerusalem-Straße 4, 38106 Brunswick, Germany
To handle these challenges, Johansen (2012) recommends four steps of business development: first, gain foresight by proactively sensing futures. In this way, companies can formulate visions that help them counter volatility. Second, develop insights to inspire strategy. The transparency thus achieved allows uncertainty to be managed. Third, gain knowledge in order to reduce complexity. Fourth, act flexible and agile against ambiguity. Tushman et al. (1996) add that companies must not only react flexibly and agilely to changes in the corporate environment, but must also organise current business processes efficiently at the same time. This ability is widely understood as "ambidextry" (Duncan 1976; Raisch et al. 2008; Tushman et al. 1996). Former research has shown that the ambidextry of successful companies is thus reflected in punctuating evolutionary developments of "cash cow and star products" ${ }^{1}$ with revolutionary developments of entirely new solutions to meet or even generate new customer needs-so-called "disruptive innovations" (Christensen 2012; Leifer et al. 2001; Prahalad and Hamel

\footnotetext{
1 According to BCG-Matrix products with above-average market
} share (Bea 2016). 
1997; Tushman et al. 1996). By this, leading firms often have to destroy current business models themselves, i.e. their own base of success, by more sustainable business models (Geissdoerfer et al. 2018). However, research has also shown that the uncertainty of the market success of revolutionary business model innovations is relatively high compared to evolutionary innovations (Assink 2006; Geissdoerfer et al. 2018). Due to this risk, numerous companies only invest in evolutionary, supposedly safe further developments of their "cash cows" and "stars". As a result, the identification and development of "question marks" 2 is often not achieved. In this case, the risk of falling into the so-called "innovator's dilemma" and being driven out of the market in the long term by more "radical innovators" 3 increases (Christensen et al. 2011).

The fact that small and medium-sized enterprises (SMEs), which represent 99\% of German enterprises (Statistisches Bundesamt 2019), fail to develop radical innovations $^{4}$ (Nielen et al. 2017) shows that those companies need support. For developing radical innovations, Furr and Dyer (2014) have built an approach consisting of the phases insight, problem definition, solution development and business model design. The approach combines the concepts of Open Innovation, Design Thinking, Lean Startup and Agile Development.

However, these concepts are first unknown by most SMEs (Dömötör 2011; Eckert 2017; Bigliardi and Galati 2016). Second, referring back to the foresight-insight-action-concept the approach by Furr and Dyer seems to lack the phase of foresight. Third, the approach does not answer how revolutionary innovations can be developed alongside evolutionary innovations.

In order to find out whether these theoretically derived research gaps really exist, five companies were interviewed who visited innovation platforms in order to find access to the solution space of radical innovations. The methods are described in Sect. 2. From these findings a process model is derived in Sect. 3 which shows how companies can achieve foresight, insight and flexible actions and at the same time

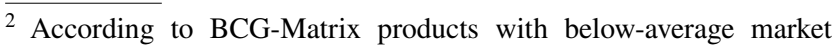
share and above-average market growth (Bea 2016)].

${ }^{3}$ Radical innovators are those who discover new, largely uncompetitive markets ("blue oceans"), shape them with their own standards and in this way build competitive advantages and scale them. As a result, they are much more undisturbed and successful than incumbents who gradually lose market share in shark basins of established markets due to competitive squabbles ("red oceans") (Kim and Mauborgne 2014)].

${ }^{4}$ As Augsdörfer et al. (2013) have shown, radical and disruptive innovations have a high degree of overlap. Since the destructive potential that distinguishes disruptive innovations from radical innovations cannot be predicted, the term radical innovation is used in the following.
}

innovate evolutionarily. These findings as well as limitations of this work are discussed in Sect. 4. Finally, Sect. 5 concludes the findings of this work and provides managerial implications.

\section{Methods}

The research question to be answered by this work is: how can companies, especially SMEs, gain foresight, insight, knowledge and act flexible in order to develop radical innovations while innovating evolutionary or efficiently at the same time?

This research question might be answered by examining the following sub-questions:

1. How can Furr and Dyer's model be complemented by ambidextry?

2. How can Furr and Dyer's model be complemented by a foresight phase?

3. How can companies get access to innovation methods in order to innovate radically?

The first question relates to the extension of the model by further scientific findings. It is therefore answered conceptually by literature research. The second question has also a conceptual part, but in addition to question one it requires methods for providing foresight. Because of that, question two and three are more explorative than the former. Case studies are suitable for scientifically answering explorative questions, as they help to gain an overview of unknown topics, to distinguish the essential from the unimportant, to abstract and to trace supposedly new back to the known (Stickel-Wolf 2005). Especially the Yin case study methodology is suitable for closing research gaps (Ridder 2017). In contrast to individual case studies, comparative case studies take a critical look at new findings by highlighting differences and similarities between the cases considered. Comparative case studies are therefore considered to be "more convincing, more trustworthy and more robust" (Borchardt et al. 2009; Eisenhardt 1989; Miles et al. 1994; Yin 2003), but are more time-consuming and costly (Yin 2003). In contrast to quantitative studies, for which representativeness large case numbers and the application of the random principle are decisive (Akremi 2014; Borchardt et al. 2009), the content spectrum of a qualitative analysis distinguishes its significance (Flick 2015). Therefore, the selection of samples in case studies can be arbitrary as long as it fits the research objective (Eisenhardt 1989; Stake 1995). Eisenhardt (1989) recommends a number of four to ten cases as a guideline, since the complexity of the evaluation also increases. In order to ensure the representativeness of the 
Table 1 Overview of companies visiting the innovation network

\begin{tabular}{|c|c|c|c|}
\hline & Company A & Company B & Company C \\
\hline Function of the experts & Product manager & CEO & Head of digitisation \\
\hline Branch & $\begin{array}{l}\text { Mechanical and plant } \\
\text { engineering }\end{array}$ & $\begin{array}{l}\text { Mechanical and plant } \\
\text { engineering }\end{array}$ & IT- and software \\
\hline Age of the company & $>50$ years & $<10$ years & $<50$ years \\
\hline Employees (2019) & $<100$ & $<10$ & $<100$ \\
\hline Revenue (2019) & $>20$ mio. Euro & $<1$ mio. Euro & $>1$ mio. Euro \\
\hline
\end{tabular}

Table 2 Overview of companies visiting the innovation lab

\begin{tabular}{lll}
\hline & Company D & Company E \\
\hline Function of the experts & Mergers and acquisition manager & Director digital transformation \\
Branch & Mechanical and plant engineering & Mechanical and plant engineering \\
Age of the company & $>50$ years & $>50$ years \\
Employees (2019) & $>499$ & $>499$ \\
Revenue (2019) & $>1$ bn. Euro & $>50$ bn. Euro \\
\hline
\end{tabular}

answer to the research question, a comparative analysis is carried out in this paper. Cases include a lab-as-a-service ${ }^{5}$ offer in Berlin and an innovation network ${ }^{6}$ of the Technical University of Braunschweig. Both cases represent innovation platforms ${ }^{7}$ for strengthening disruptive innovations in SMEs and are therefore subject to homogeneous framework conditions. Due to a limited time frame, the number of cases is lower than suggested by Eisenhardt (1989).

Since no data is yet available to answer the research questions, the data collection must take place primarily within the cases. According to Beutin (2008, p. 821), expert interviews guarantee the highest degree of participation, flexibility, interaction and external validity. Experts from mediumsized companies who have already visited an innovation platform are considered to be experts to answer the research question. They are interviewed semi-structured in order to be able to ask questions and at the same time allow a certain

\footnotetext{
5 According to Gryszkiewicz et al. (2016, p. 16) "an innovation lab is a semi-autonomous organisation that engages diverse participantson a long-term basis-in open collaboration for the purpose of creating, elaborating, and prototyping radical solutions to open-ended systemic challenges." While innovation labs often belong to a large parent organisation, the concept of "lab as a service" refers to such labs "offering services such as designing the idea-generation processes, planning or carrying out real-world tests of innovations, and pre-market launch assessments" to third parties.

${ }^{6}$ According to Gryszkiewicz et al. (2016, p. 16) innovation networks bring together dispersed actors and foster the exchange of information.

7 According to Duden (2018), a platform is a "place or group of people that serves the exchange and dissemination of ideas, views or products" [191]. According to Gryszkiewicz, the following exist in the context of support services for disruptive innovations: hubs, inhouse R\&D labs, communities of practice, living labs, innovation labs, innovation networks and innovation task forces.
}

comparability of the interviews. These were the five main questions asked:

1. What was the innovation behavior of companies in terms of producing radical innovations before

2. visiting the innovation platform?

3. What was the motivation to visit an innovation platform?

4. What selection criteria were used to choose a suitable innovation platform?

5. What was the use of the innovation platform like?

6. What is the innovation behavior of the companies with regard to the production of radical innovations after the platform visit?

Tables 1 and 2 show the characteristics of the interviewed expert's companies.

Based on the interviews and the findings from literature research a model is built that answers the three research questions. The model is validated via testing by company $\mathrm{B}, \mathrm{D}$ and $\mathrm{E}$.

\section{Results}

In order to answer the three research questions this chapter is divided into the three respective parts, before testing the developed model: First, the extension of the approach according to Furr and Dyer with the concept of ambidextry. Second, the extension of the approach to the foresight phase. Thirdly, providing methods for radical innovator's in order to gain insights and act flexible. 


\subsection{The extension of the approach according to Furr and Dyer with the concept of ambidextry}

As shown in the introduction of this paper most established companies tend to fall into the trap of "innovator's dilemma" since their success is based on high effiencies and the flexibility needed to develop revolutionary innovations does not seem affordable. To avoid this, companies must constantly identify ways to cannibalize their technologies and business models. To succeed with that, the cash flow from key and basic technologies can be used to invest early in the development of pacemaker technologies. Therefore, companies need an organizational structure that, in addition to enablers of evolutionary innovations, also realizes enablers of disruptive innovations. Due to the competitive situation of evolutionary and disruptive innovations, Christensen et al. and Pinkwart et al. recommend separating the development of disruptive innovations and the associated risk from the development of evolutionary innovations: "Instead of constantly having to work on convincing individual employees of the usefulness of a small, disruptive project that could at some point be important or strategically significant, it is much easier to assign such projects to a small organizational unit for which a small, newly emerging market also represents a great opportunity." The outsourcing of activities that are associated with disruptive innovations enables the decoupling of prevailing ways of thinking and viewing within the company. This is decisive for the formation of an own business model, the development of an independent organizational culture as well as the access to new customers (Christensen et al. 2011, p. 110). In addition, the tasks of disruptively innovating units are usually associated with a high risk. The separation of the core business and future business model developments thus offers the possibility of separating the associated risk from the core business and, if necessary, disposing of it in the event of failure (Pinkwart et al. 2015, p. 355).

According to Christensen et al. (2011, p. 162) this can happen in two ways: The first option is a collaboration between start-ups, which as a rule have predominantly enablers for producing disruptive innovations (cf. Markides and Geroski 2004, p. 66; Markides 2006, p. 24), and established organisations, which are characterised by competences for scaling innovations (Deloitte Research 2017, p. 17, 20, 21). The second possibility for established companies-provided they have sufficient internal idea generators and implementers ("intrapreneurs")—is to spin off a part of the company that "does not, no longer or not yet belong to the current core business of the parent company, but nevertheless has promising business prospects" (Manager Magazin 2007; cf. Christensen et al. 2011, p. 162). In both cases, it is necessary to decide which measure of integration makes sense. Thus, with an increasing degree of integration for the parent organisation, the opportunities for participation increase, but at the same time the autonomy and the incentive to independently improve the performance of the subsidiary organisation or the cooperation partner are reduced.

With this background, Fig. 1 shows how a dualism of two organizations equipped with the respective enablers of evolutionary and disruptive innovations can enable ambidextry. According to Christensen et al. (2011, p. 110), both organisational units are characterised by their own business model, their own organisational culture and their own customers. According to Akpinar (2014, p. 6), the tasks of the organization tasked with disruptive innovations consist of the following

1. Identification of new markets

2. Use resources to develop and market disruptive innovations

3. Use agile methods to develop disruptive innovations

4. Marketing of disruptive innovations.

This model answers the first research question of how the model by Furr and Dyer can be extended to the concept of ambidextry.

In the following section the second research question about the extension of the approach to the foresight phase is answered.

\subsection{The extension of the approach to the foresight phase}

According to Johansen, the foresight phase is designed to help companies develop a vision to manage the volatility of the surrounding world.

The interviews have shown that companies, which still draw on past successes, often have little foresight with regard to the threats emanating from the VUCA situation. The low proportion of innovators in small and mediumsized enterprises indicates that the majority of SMEs can be counted among such enterprises. So how can those companies be enabled first, to determine their current strength regarding VUCA, second, identify relevant future trends and then third, find radical innovators who share the company's vision and are already testing a way to engage with the identified future trends? These three steps are visualized in Fig. 2 and described in the following.

\subsection{Determining the status quo of the company's VUCA resilience}

In order to find out how much a company is already working towards exploiting future trends and thus building stability with regard to VUCA, it makes sense to first analyse the company's current business model. Why do 


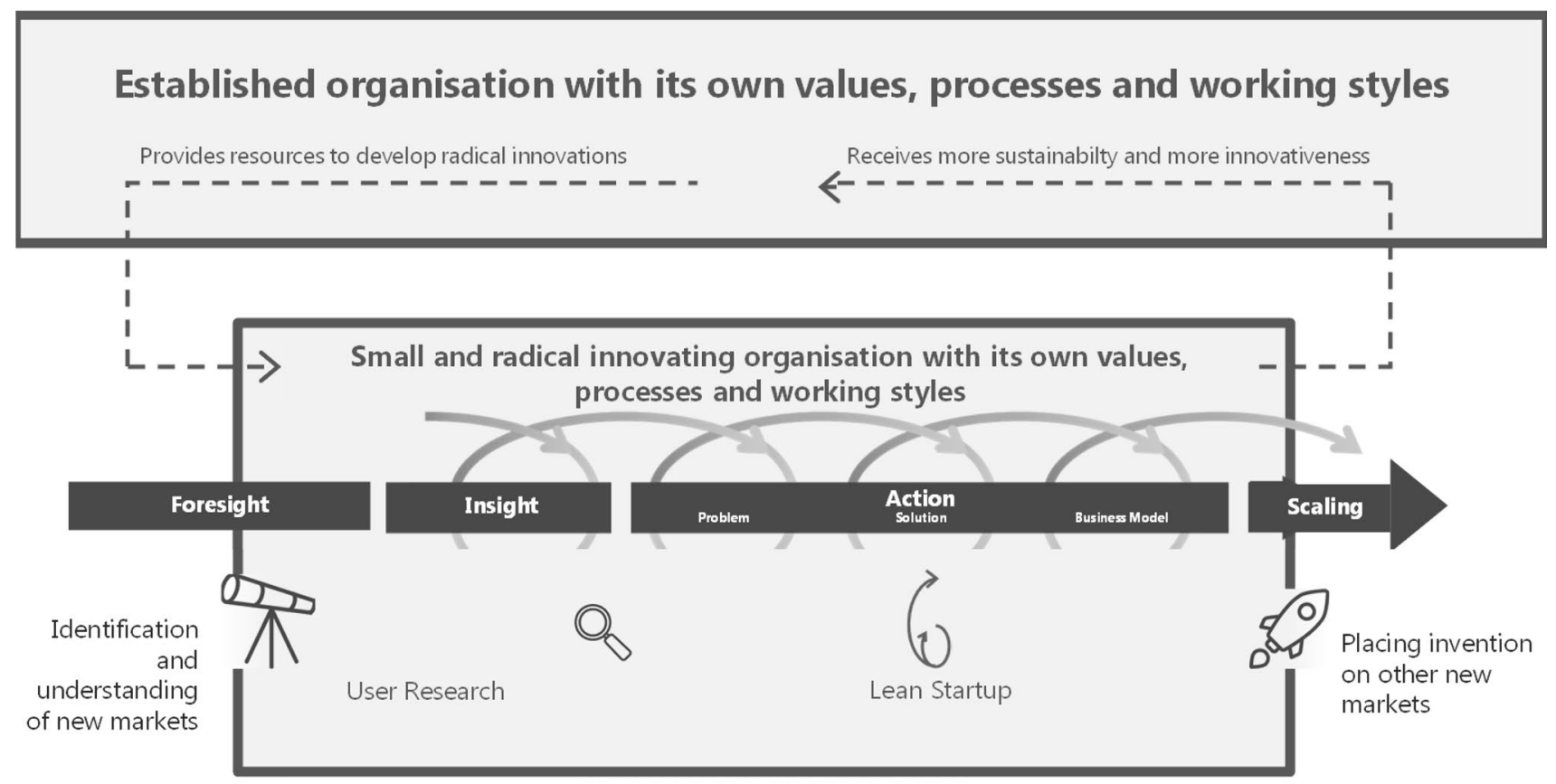

Fig. 1 Extend "The Innovator's Method" by Furr and Dyer to the concept of ambidextry and a foresight phase

\section{Foresight}

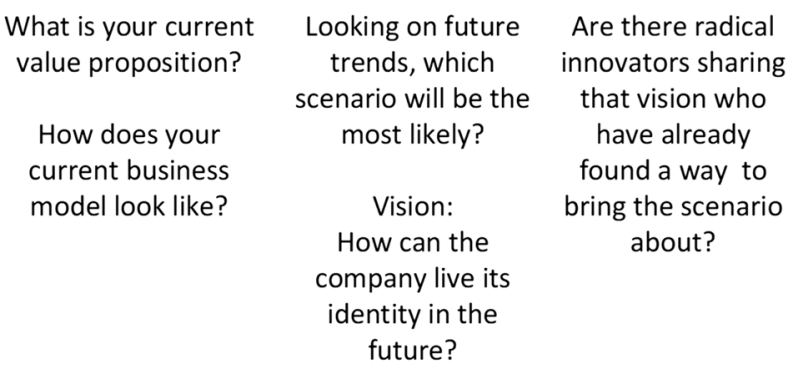

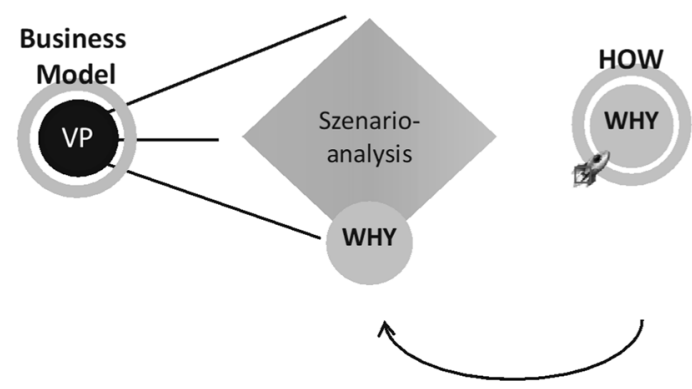

Fig. 2 The foresight phase consists of deriving the company's value proposition from its current business model, challenging it with a scenario analysis and finding radical innovators who try to find the best way in order to bring the most likely scenario about customers love the brand and its products? What is the value proposition that the current business model is based on? Therefore, the business model canvas by Osterwalder and Pigneur can be used as well as the Value Proposition Canvas by Osterwalder. By filling in both canvases, the foundations on which a company is based are uncovered and can be tested for VUCA resistance by asking: Does the company already have a vision of how it wants to live up to its value proposition with regard to future trends?

In the event that a company finds that the vision of the current business model does not seem resilient enough to cope with VUCA, the following steps will help identify relevant future trends, create a suitable vision and then find people who can develop solutions beyond the core business to live that vision.

\subsection{Identifying relevant future trends: what scenario might be the most likely?}

Since it is impossible to anticipate the future exactly, companies should invest in several possible scenarios. The scenario method proposes to give companies a scientific decision-making basis and long-term planning instrument for strategy and corporate development. By this, companies should become able to better assess the opportunities and risks of the future. To get there, the scenario analysis uses the following three steps shown in Fig. 3. 


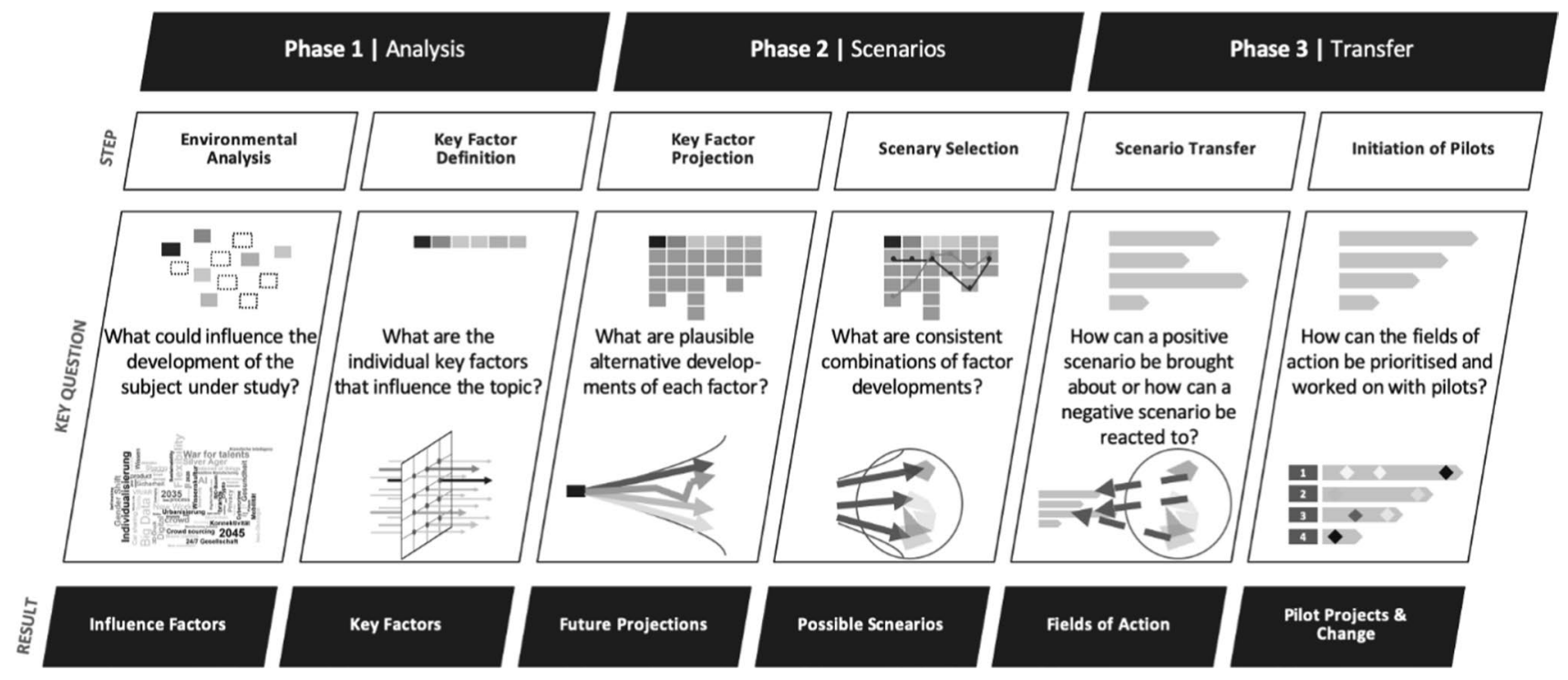

Fig. 3 Three-phase approach to scenario analysis (Schaupensteiner and Weiß 2018)

The steps shown in the Fig. 3 are now going to be described in more detail. Future scientists can help to apply these steps, successfully.

\subsubsection{Phase 1: Identification of influence and key factors for the company's specific problem}

In order to identify relevant future influencing factors for the company, it is advisable to start with megatrends and derive sub and project-specific trends from them.

The German Zukunftsinstitut (2019) has identified twelve generally recognized megatrends: Knowledge Culture, Urbanization, Connectivity, Individualization, Neo-Ecology, Globalization, Gender Shift, Health, New Work, Mobility, Silver Generation, Security. For each of these megatrends, the Zukunftsinstitut has created a map of subtrends as well [ib]. On the basis of these sub-trends, company-specific trends can be derived by the companies themselves and critically questioned by consultants. In this way, companyspecific problems can be identified with a view to the future. Trends that are highly relevant to these problems are considered key factors.

\subsubsection{Phase 2: Projection of key factors and selecting plausible combinations as future scenarios}

For each key factor plausible alternative developments can be developed reaching from a worst-case scenario to a bestcase scenario. Then bundles of these projections can be created and checked for plausibility by applying consistency analysis and cross impact analysis.

\subsubsection{Phase 3:Transfer how a positive scenario can be brought about or how a negative scenario can be reacted to. Initiation of pilot projects}

Sinek (2009) has found out that people do not buy "what you do; they buy why you do it. And what you do serves as the tangible proof of why you do it." Although business models can become outdated, the answer to the question "Why?" is much deeper and more resistant to VUCA than the "How" expressed in the business model. Because of that, companies define in this phase first a vision why they want to live their value proposition in the future. Once a company has defined this "Why" or its vision, it can start looking for people who are willing to take the risk to explore the "how" and by "what" the scenario can be brought about (see Sect. 1 of this chapter). As these questions call into question the business model of the core organisation, it is advisable, analogous to Sect. 1 of this chapter, to delegate this task to radical innovators outside the core company. These so called radical innovators are people who try to answer the same "why", but with probably more sustainable and at the same time more inexperienced and risky "hows".

Finding those radical innovators and getting in contact with them is the next and last step of the foresight phase.

Finding radical innovators who share the company's vision and are already testing a way to engage with the identified future trends. These people are about to destroy the company's business model. Ask them for their vision and engage with the right ones.

There are two ways to find radical innovators either inside or outside the company: Either companies do their own research or they ask Startup Locators and 
Accelerators in order to get suggestions for suitable startups and get in contact with them.

The following criteria might help companies to evaluate how these radical innovators are trying to answer the shared vision identified in the scenario analysis before (Beamberlin 2019):

1. The non-obvious question: have they identified a unique opportunity that others don't see?

2. The unfair advantage question: is the problem highly relevant for customers that especially the companys has access to?

3. The timing question: is now the right time to start this particular business?

4. The superiority question: is the solution to the problem at least $5 \mathrm{X}$ better than the status quo?

5. The monopoly question: are we starting with a big share of a small market?

6. The defensibility question: will our market position be defensible 10 and 20 years into the future?

7. The vision question: Compelling answer to: how big could this idea/the company become if our founders executed very well? $€ \times 00$ million? $€$ billions?

8. The engineering question: can we create breakthrough technology instead of incremental improvements?

9. The distribution question: would we have a way to not just create but deliver the product?

If a company feels that the met innovators have a promising answer to these nine questions, the decision for a cooperation in the form of an internal spin-off or external investment can be made for example depending on transaction cost theoretical considerations. Since trust and shared values are not included in the transaction cost theory, they must be considered as well.

In this section it has been shown how business principles can be questioned regarding VUCA, how a vucastable vision can be defined and appropriate radical innovative ones can be found. Together with the concept of ambidextry added to the model in the first step, companies are now able to innovate more ambidextrously regarding VUCA. With step two they now own a guide with which they can select the right radical innovations. With that the "Innovator's method" by Furr and Dyer is extended to a foresight-phase and research question number two is answered.

With regard to the last research question, the following section describes methods with which startups or spin-offs ("radical innovators") can agilely develop usercentric solutions and successfully place them in the right markets.

\subsection{Providing methods by which SMEs receive through radical innovators access to insights and flexible actions}

The interviews have confirmed that the inoculation of "radical" methods into established companies hardly works due to the conflicting demands of radical and evolutionary innovations. Access to radical innovation methods is therefore best given to SMEs by leaving radical innovation to start-ups, but being familiar with the methods and open to mutually respectful exchange. In the following, therefore, methods are described which are primarily to be applied by the radical innovators, but must nevertheless be understood by the SMEs and recognised in their raison d'être.

Figure 4 shows how the whole ambidextrous foresightinsight-action-model between established organisations and radical innovators works. Beginning with the foresight phase which was described in the previous section, the model shows how radical innovator's gain deeper insights by finding and investigationg real people who share their mission. The dotted lines mark termination points. If there are no people who share the radical innovator's mission, new radical innovators with a more promising mission have to be found. Its phases are described in the following.

Finding real future customers who share the radical innovator's values and who benefit from the innovator's vision. Making the vision clear to potential customers and seeing how they will react. Do they love the concept? Will they be first customers?

In this phase it should be asked if there are already people who are interested in the radical innovator's vision and who will benefit from it. The methodical approach is based on the insight that people with common values have a high probability of sympathy.

The first step for finding potential customers is to create a persona that reflects all the qualities of the radical innovator and its vision. For this step the persona template from Lewrick et al. (2018) can be recommended.

The next step is to check whether there are real customers that match with that fictive persona. For this purpose, radical innovators can create an empathy map supplemented by locations (Fig. 5) that describes where people similar to the persona could be found. By this the radical innovators receive a starting point where such real persons can be met in order to validate their initial assumptions documented with the persona. Since there may still be too many people at places of empathy among whom the people most in agreement with the persona must be identified, hints like "hashtags" that would be used by the persona 


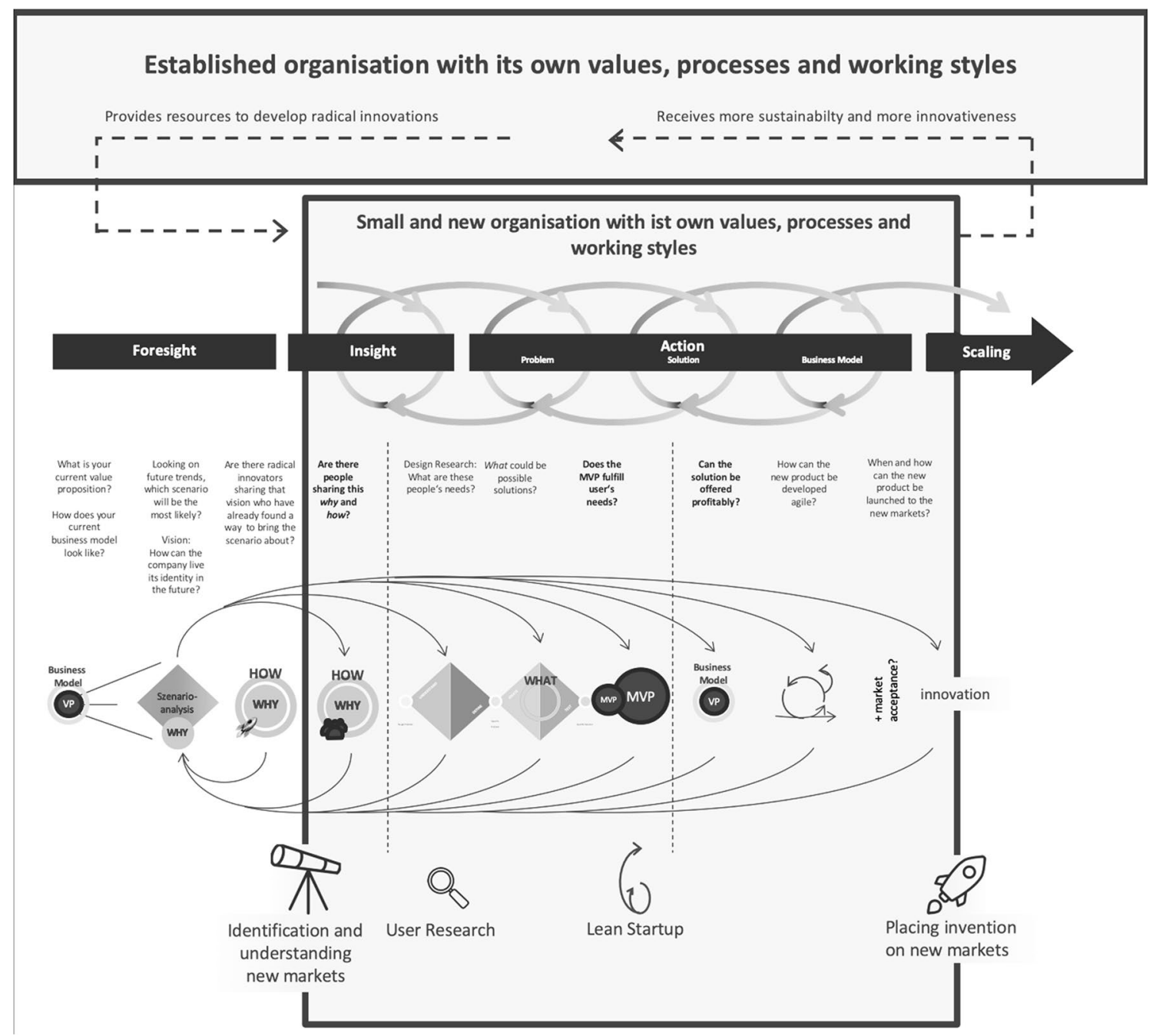

Fig. 4 Concept to prepare leaders to handle the challenges of digital transformation and complexity

for example on Instagram or LinkedIn ${ }^{8}$ can be another instrument to get to the most relevant people. If this is not possible, market research institutes can be asked for help.

Having identified real people who correspond to the radical innovator's vision, these people's problems regarding the vision have to be uncovered in order to provide and test fitting solutions for them. Therefore, the double diamond model of design thinking shown in Fig. 6 can be used. In the event that no real persons could be identified, the incumbent must first verify whether its assumptions about the most likely scenario are still true. If these assumptions are still correct, it is clear that the solution of the selected radical innovator is not appropriate. In this case, the step towards the search for radical innovators must be repeated.

\footnotetext{
${ }_{8}^{8}$ Depending on the context of the vision for that "research objects" should be found.
}

The core concept of this double diamond model is to open the problem space by interviewing and observing people how they do certain things ("understand"). In the second step, challenges while doing the certain things are defined and prioritized ("define"). The result is the identification of a specific problem that is most critical to be solved to relieve user's pains. In the second diamond, the solution space gets opened by ideating about possible solutions ("ideate"). Via prototyping and testing the ideated possibilities, a specific solution can be identified ("test"). While doing this the validity of the assumptions made always has to be checked ("iterate").

In the following three steps the use of the double diamond approach is described more detailed.

Design Research Diving into the target group's current problems regarding the radical innovator's vision. What will be customer's needs in the future the innovator wants to create? 


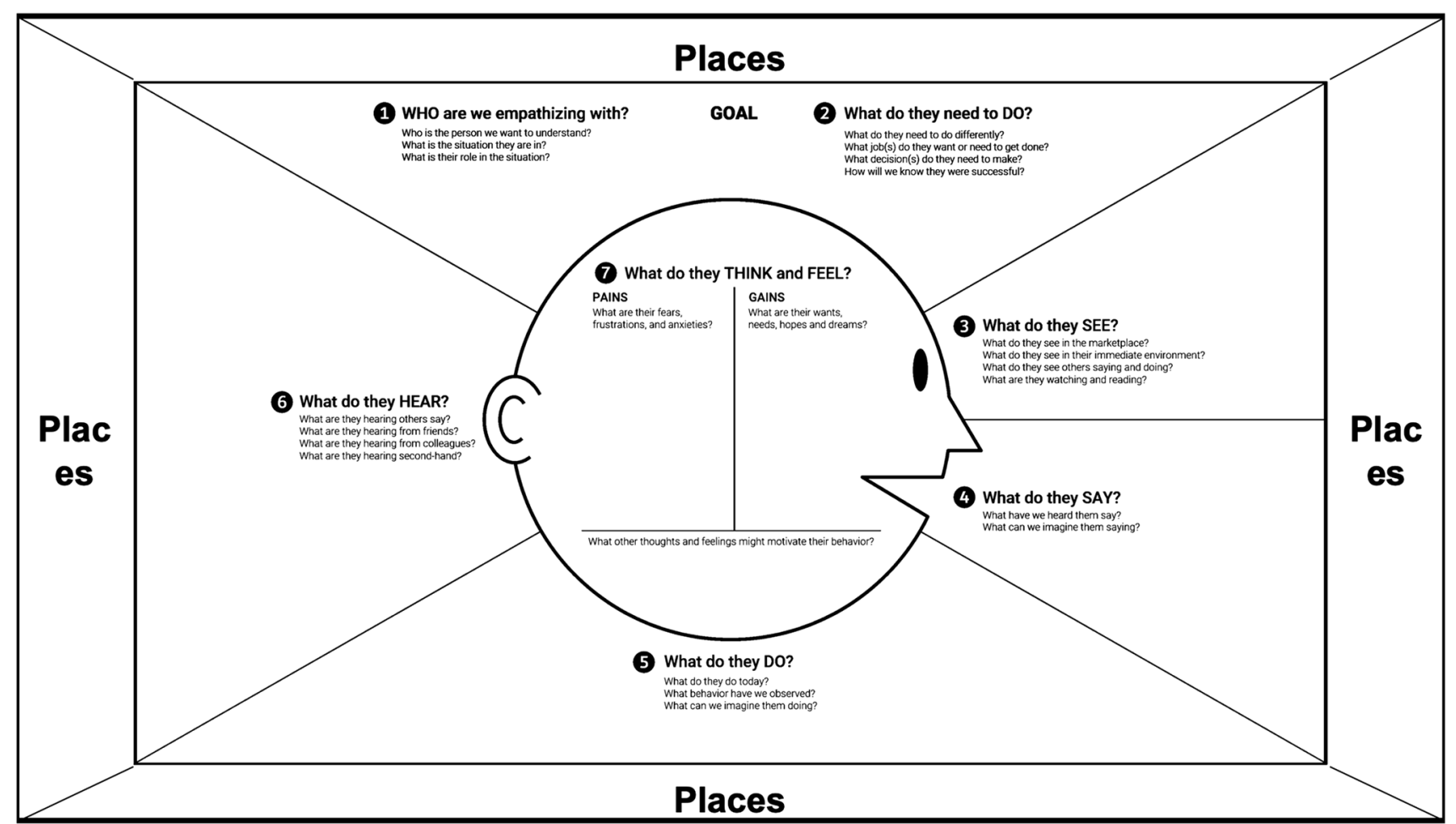

Fig. 5 Empathy map supplemented by places where people represented by the persona can be found (inspired by Gray 2017)

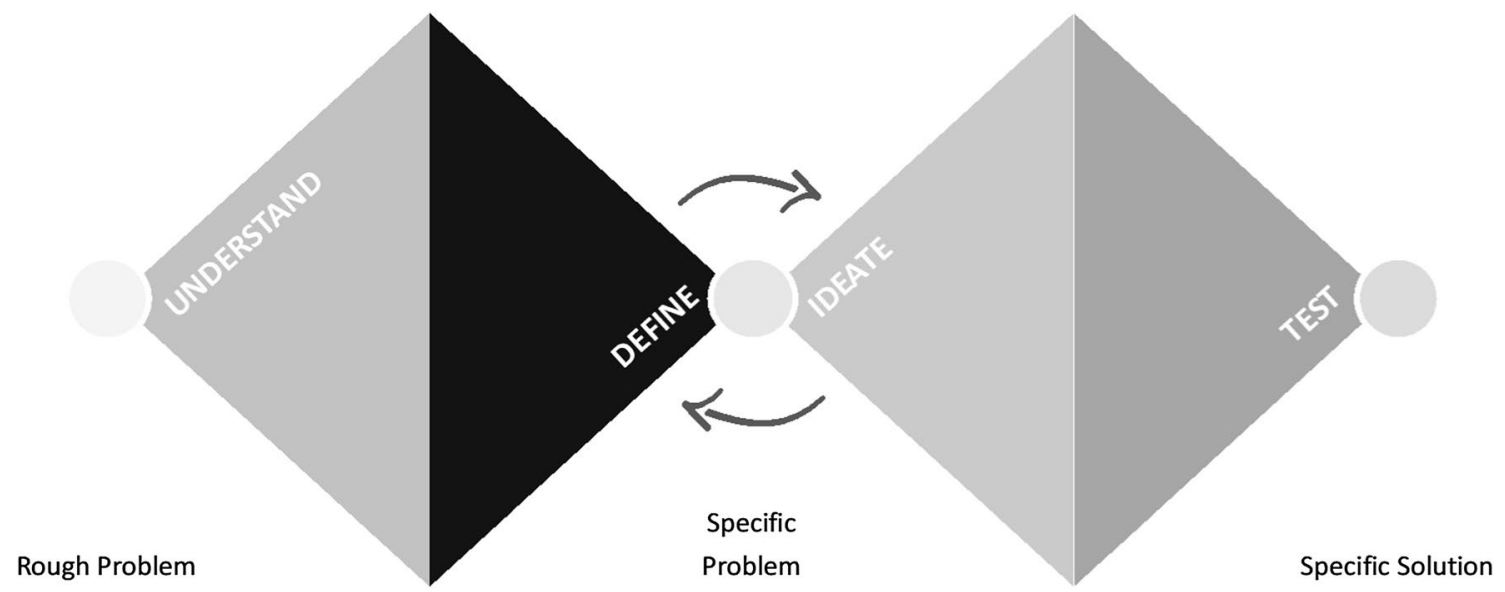

Fig. 6 Double diamond model [MHP (2020), inspired by British Design Council (2007)]

The task of radical innovators is to solve their future customer's needs in relation to the vision examined. In order to identify these tasks, it is advisable to observe the people in action and ask why they are doing certain things in certain ways. Classic methods of market research, such as observations and surveys, are suitable for this purpose. In order to structure the findings, it is advisable to fill in the customer profile of Osterwalder et al. (2014).

To close the first diamond, the most critical problem has to be identified. Therefore, methods like axis mapping in terms of urgency and importance can be helpful. To solve the identified specific problem, the second diamond must be opened.

Ideation about how the specific problem can be solved and creating a value proposition.

The second half of the double diamond model refers to creating solutions for the previous identified problems. In the ideation as much ideas as possible should be created. The value map of Osterwalder et al. (2014) is a helpful tool to brainstorm every possible way to solve a problem. 
To stimulate creativity, methods like the headstand method can be used (Dark Horse Innovation 2016).

In order to select the most promising idea, a comparison should be made with the customer profile filled in during the first design research phase (first diamond). Further sorting out can be achieved by point scoring (each team member sticks a point on the idea he or she favors most). For presenting the winning idea to the customers and have it tested by them, a value proposition should be formulated: what are pain relievers of the solution, what are gain creators in order to complete a certain task. In order to later create a business plan, the price of the future product should be considered at this phase, too.

Building a MVP in an agile way and accepting failure as critical to success. Testing the MVP as soon as possible with value sharers, defining new hypotheses, improving the MVP, testing it, ... build, measure, LEARN.

In order to close the second diamond and check whether customers also prefer the same solution and price as the radical innovator, a fast prototype or minimum viable product (MVP) must be built and made available to the customers for testing. The value proposition canvas helps to keep the initial goal in mind (Osterwalder et al. 2014). In order to be as close as possible to the possibly changing customer requirements, it is advisable to iterate quickly, as the lean startup methodology provides: build a MVP, measure the customer feedback and learn from it.

Price acceptance of the future customers is an important factor for keeping an eye on the costs of product development and being able to communicate with any necessary investors. A tool for that is described in the next step.

Creating a business plan and a new business model.

Up to this point, the radical innovator has built a MVP for a small group of customers who will benefit from the solution and from whom it is believed there will be more followers of this group in the future.

The next step is to ask when the critical time will be reached to bring the product to market and how this should be done. A business plan and a new business model can be drawn up for this and must be regularly aligned and adapted to market changes. With this radical innovators can pitch the concept to investors and gain further money in order to develop a real product.

Starting to build the product agile while checking again and again if the assumptions made in the previous phases are still valid.

Once the future customers are happy with the MVP, the radical innovator can start to deveop a real product. Agile development has the advantage of being able to adapt quickly to changing environmental influences (VUCA). For this purpose, the assumptions of the previous phases must be regularly reviewed and, if necessary, adapted. One method that has proven itself in an agile environment is scrum (Schwaber and Beedle 2002).

Bringing the new product to market, tracking its financial success as well as user satisfaction, continuing to explore user needs, challenging the business model with new trends and applying these ten steps again.

With the business plan and business model the radical innovator has a schedule how and when to introduce the product to relevant markets. The iterative approach presented in this paper should help radical innovators to meet the needs of an emerging and promising market. However, radical innovators should track the user satisfaction as carefully as they will probably track the financial success of the product. It is important to stay tuned for new customers, know them deeply and have a close relationship with them. But again, falling into an innovator's dilemma by focusing too much on them has to be avoided. The business model has to be always requested with emerging trends.

\subsection{Testing the model}

The model described in the three previous sections is based on interviews with five German SMEs. At the time of this paper, the model has been tested with three of these five interviewed companies (Company B, D and E). As a result, after almost three years after first getting in contact with them, company $\mathrm{D}$ and $\mathrm{E}$ have opened up a company builder in startup metropolises Berlin and Munich in order to participate in radical innovations. For example, the nine questions for identifying suitable radical innovators (foresight phase) were developed in one of these company builders and then incorporated into the model described in this paper. Due to its limited financial resources company B limits itself to frequent visits to innovation platforms to get in touch with radical innovators. Further validation of the model by companies of other sizes and countries is planned.

\section{Discussion}

This paper is based on the fact that most German companies innovate evolutionary but miss investments in radical innovations. With a view on the VUCA phenomenon it was pointed that an ambidextrous management of evolutionary and revolutionary innovations is necessary ,in order to reconstruct a new organization better suited for the next wave of competition or technology" (Tushman et al. 1996).

By literature research it was shown that the ForesightInsight-Action-Concept lacks methods in order to provide VUCA-resilience to companies. Most of those methods could be found in the "Innovator's Method" by Furr and Dyer (2014). However, the authors do not provide methods for the foresight phase. In addition, neither the Foresight-Insight-Action-oncept 
nor the Innovator's Method integrate the concept of ambidextry.

Therefore, this paper raised the following research question: How can companies, especially SMEs, gain foresight, insight, knowledge and act flexible in order to develop radical innovations while innovating evolutionary or efficiently at the same time?

This research question was answered by examining the following sub-questions:

1. How can Furr and Dyer's model be complemented by ambidextry?

2. How can Furr and Dyer's model be complemented by a foresight phase?

3. How can companies get access to innovation methods in order to innovate radically?

The first question was answered by a construct in which the development of evolutionary developments is the responsibility of the established companies, while they participate through collaboration in radical developments through separate organizational units apart from the core organization. By separating the radical innovations from the core business, the undisturbed development of these solutions becomes possible on the one hand and the associated risk is outsourced on the other. This construct is based on and evidenced by the findings of Christensen et al. (2011) among others.

Research questions 2 and 3 have been answered based on the findings of the Innovator's Method and with the help of five semi-structured expert interviews. The interviews proved to be a thorough, but time-consuming, tool to gain insights into the innovation behaviour of companies. Alternatively, standard surveys could have been carried out, but these would probably have provided less in-depth insights.

The result is a model that has already been tested with three of the five interviewees. In these three cases it has helped to give companies foresight, access to radical innovators and achieve ambidextry. Nevertheless, further cases of companies of different sizes and countries are needed to further validate the model.

Since this paper shows only the ideal way for established companies to reach ambidextry with the help of radical innovators, further research is needed to look at cases such as when no radical innovators can be found to develop solutions for the identified scenario. Another case to be clarified refers to such scenarios for which "test customers" cannot yet be identified.

\section{Conclusion and managerial implications}

The model presented in this paper aims to give companies methodological access to foresight in order to collaborate with radical innovators and thus achieve ambidextry. The created model is based on both theoretical knowledge and practical experience. Scientific methods from the fields of Scenarios and Strategy, Design, Lean Startup and Business Modeling ensure a future-oriented, strategically thoughtthrough, user-oriented and agile approach. Practical surveys investigating the contribution of innovation platforms to the radical innovation behaviour of established companies help to provide companies with practical guidelines for finding access to the solution space of radical innovations.

As a conglomerate of scientific and practical findings, a ten-step model has emerged that helps established companies question their current business model with regard to future trends, identify radical innovators who could become a threat, and collaborate with them.

In detail, this involves deriving the company's value proposition from the current business model, identifying future trends with the help of scenario analysis, questioning the future viability of the current business model and searching for radical innovator's that try to destroy the company's current business model in a promising way. Moreover, potential customers with same values as the radical innovators have to be identified. Future user problems must be understood, and suitable solutions developed. A MVP has to be built, a business plan and new business model set up. Agile product development and a well organised market launch are crucial , in order to reconstruct a new organization better suited for the next wave of competition or technology" (Tushman et al. 1996).

Validations of the model have brought about almost disrupted, rural companies opening up a company builder in startup metropolises Berlin and Munich to participate in radical innovations. Further validations can be achieved by testing the model by companies of other sizes and countries.

As managerial implication for possibly similar endangered company, it is crucial to first identify why customers love the company's products and brand. Therefore, customer satisfaction should be taken seriously. However, too much focusing on current's customer satisfaction leads into the trap of the innovator's dilemma. The answer of how the company currently solves user problems thus has to be challenged with future trends. At this stage, companies should not hesitate to contact future scientists, in order to evaluate the relevance of future trends, independently and without being dazzled by past experiences.

The next thing to do, is to overcome personal prejudices and fears about startups. $90 \%$ of startups fail since scaling competences already gained by established companies are missing (Patel 2015). On the other hand, especially SMEs tend to underestimate the potential of disruptive technologies and business models. Uncommitted exchange thus helps to identify other ways of solving a problem. Moreover, personal exchange helps evaluating whether a met startup might 
be a promising collaboration partner (Nalebuff and Brandenburger 2008).

Since the development of evolutionary and revolutionary solutions requires very different conditions, startups and established companies work very differently. In order to help them collaborating, companies should not hesitate to seek advice from consultants specializing in cooperation between corporates and startups. The way companies and startups want to go has never been gone before. Therefore, it is important that both can focus on their individual strengths while consultants can help to keep the goal in mind and test potential solutions iteratively with customers.

Open Access Dieser Artikel wird unter der Creative Commons Namensnennung 4.0 International Lizenz veröffentlicht, welche die Nutzung, Vervielfältigung, Bearbeitung, Verbreitung und Wiedergabe in jeglichem Medium und Format erlaubt, sofern Sie den/die ursprünglichen Autor(en) und die Quelle ordnungsgemäß nennen, einen Link zur Creative Commons Lizenz beifügen und angeben, ob Änderungen vorgenommen wurden. Die in diesem Artikel enthaltenen Bilder und sonstiges Drittmaterial unterliegen ebenfalls der genannten Creative Commons Lizenz, sofern sich aus der Abbildungslegende nichts anderes ergibt. Sofern das betreffende Material nicht unter der genannten Creative Commons Lizenz steht und die betreffende Handlung nicht nach gesetzlichen Vorschriften erlaubt ist, ist für die oben aufgeführten Weiterverwendungen des Materials die Einwilligung des jeweiligen Rechteinhabers einzuholen. Weitere Details zur Lizenz entnehmen Sie bitte der Lizenzinformation auf http://creativecommons .org/licenses/by/4.0/deed.de.

\section{References}

Akpinar M (2014) Challenges and success factors in pursuing disruptive innovations: a finnish high-tech start-up case study (2014). Retrieved April 24, 2018 from http://verkkolehdet.jamk.fi/finni sh-business-review/2014/09/08/2014-1/

Akremi L (2014) Stichprobenziehung in der qualitativen Sozialforschung. In: Nina B, Jörg B (eds) Handbuch Methoden der empirischen Sozialforschung. Springer, Wiesbaden, pp 265-282

Assink M (2006) Inhibitors of disruptive innovation capability: a conceptual model. Eur J Inf Manag 9(2):215-233. https://doi. org/10.1108/14601060610663587

Augsdörfer P, Möslein K, Richter A (2013) Radical, discontinuous and disruptive innovation - what's the difference. Discontinuous innovation: learning to manage the unexpected, pp 9-39

Beamberlin. Retrieved August 9, 2019 from https://beamberlin.com/ how-we-invest/. Accesed 21 Nov 2019

Beutin N (2008) Messung von Kundenzufriedenheit und Kundenbindung. Handbuch Marktforschung: Methoden-AnwendungenPraxisbeispiele 3:813-846

Bigliardi B, Galati F (2016) Which factors hinder the adoption of open innovation in SMEs? Technol Anal Strat Manag 28(8):869-885. https://doi.org/10.1080/09537325.2016.1180353

Borchardt A et al (2009) Erkenntnisgewinnung durch Fallstudien. Methodik der empirischen Forschung. Springer, New York, pp 33-48

British Design Council (2005) The design process: the 'double diamond'design process model. http://www.designcouncil.org. uk/about-design/how-designers-work/the-design-process/. Acesso em, 11(12), 2013
Christensen C, Matzler K, Eichen SF (2011) The Innovator's Dilemma. Warum etablierte Unternehmen den Wettbewerb um bahnbrechende Innovationen verlieren. Franz Vahlen, München

Christensen C (2012) Disruptive innovation (2012). Retrieved May 11, 2018. https://www.claytonchristensen.com/key-concepts/. Accesed 21 Nov 2019

Dark Horse Innovation (2016) Digital Innovation Playbook: Mit neuen Produkten und Services die Zukunft gewinnen. Murmann Publishers. https://digital-innovation-playbook.de/images/templates pdf/6_3_13_EXPLORE-METHODE-8.pdf. Accesed 21 Nov 2019

Deloitte Research (2017) Kooperationen zwischen Mittelstand und Start-ups (2017). Retrieved August 21, 2018 from https://www2. deloitte.com/de/de/pages/mittelstand/contents/Studienserie-Erfol gsfaktoren-im-Mittelstand.html

Dömötör R (2011) Innovation und Mittelstand. In: Dömötör R (ed) Erfolgsfaktoren der Innovativität von kleinen und mittleren Unternehmen. Zugl.: Wien, Wirtschaftsuniv., Diss., 2007, Innovation und Entrepreneurship. Gabler Verlag/Springer Fachmedien Wiesbaden GmbH Wiesbaden, Wiesbaden, pp 6-25

Duden (2018) Plattform. Rechtschreibung, Bedeutung, Definition, Synonyme. Retrieved June 20, 2018. https://www.duden.de/rechtschre ibung/Plattform. Accesed 21 Nov 2019

Duncan RB (1976) The ambidextrous organization: designing dual structures for innovation. Manag Organ 1:167-188

Eckert R (2017) Lean Startup in Konzernen und Mittelstandsunternehmen: Ergebnisse einer Expertenbefragung. In: Roland E (ed) Lean Startup in Konzernen und Mittel-standsunternehmen. Ergebnisse einer Expertenbefragung und Handlungsempfehlungen. Springer Gabler, Wiesbaden, pp 17-31. https://doi. org/10.1007/978-3-658-15775-3_3

Eisenhardt KM (1989) Building theories from case study research. Acad Manag Rev 14(4):532-550

Flick U (2015) Design und Prozess qualitativer Forschung. In: von Kardorff E, Steinke I, Flick U (eds) Qualitative For-schung: Ein Handbuch. Rowohlt Taschenbuch-Verlag, Reinbek bei Hamburg, pp 252-265

Furr N, Dyer J (2014) The innovator's method: bringing the lean startup into your organization. Harvard Business Press, Cambridge

Geissdoerfer M, Vladimirova D, Evans S (2018) Sustainable business model innovation: a review. J Clean Prod 198:401-416

Gray D (2017) Retrieved August 9, 2019. https://medium.com/thexplane-collection/updated-empathy-map-canvas-46df22df3c 8 a. Accesed 21 Nov 2019

Gryszkiewicz L et al (2016) Innovation labs: leveraging openness for radical innovation? SSRN J. https://doi.org/10.2139/ssrn.2556692

Johansen B (2012) Leaders make the future. Ten new leadership skills for an uncertain world, 2nd edn. Berrett-Koehler Publishers, San Francisco

Kim WC, Mauborgne RA (2014) Blue ocean strategy, expanded edition: how to create uncontested market space and make the competition irrelevant. Harvard Business Review Press, Cambridge

Leifer $\mathrm{R}$ et al (2001) Implementing radical innovation in mature firms: the role of hubs. Acad Manag Exec 15(3):102-113

Lewrick M, Link P, Leifer L (2018) The design thinking playbook: mindful digital transformation of teams, products, services, businesses and ecosystems. Wiley, Hoboken

Manager Maganzin (2007) Was ist eigentlich: Die Ausgründung? manager magazin (January 2007). Retrieved August 21, 2018 from http://www.manager-magazin.de/unternehmen/karriere/a458669.html

Markides C (2006) Disruptive Innovation: in need of better theory*. J Prod Innov Manag 23(1):19-25. https://doi.org/10.111 1/j.1540-5885.2005.00177.x

Markides CC, Geroski PA (2004) Fast second: How smart companies bypass radical innovation to enter and dominate new markets. Wiley 
MHP (2020) Consultation document (can be provided by the author upon request)

Miles MB, Huberman AM (1994) Qualitative data analysis: an expanded sourcebook. Sage, Thousand Oaks

Nalebuff BJ, Brandenburger AM (2008) Coopetition: kooperativ konkurrieren-Mit der Spieltheorie zum Geschäftserfolg, 2nd edn. Rieck, Eschborn

Nielen S et al (2017) Disruptive Innovationen: Chancen und Risiken für den Mittelstand. IfM-Materialien, Institut für Mittelstandsforschung (IfM), Bonn

Osterwalder A, Pigneur Y, Bernarda G, Smith A (2014) Value proposition design: how to create products and services customers want. Wiley, Hoboken

Patel N (2015) 90\% of startups fail: here's what you need to know about the 10\%. Forbes (online). https://www.forbes.com/sites/ neilpatel/2015/01/16/90-of-startups-will-fail-heres-what-youneed-to-know-about-the-10/

Pinkwart A et al (2015) Venture Capital-Finanzierung im Mittelstand. In: Georg F, Arndt GK, Diethard BS (eds) Mittelstand - Motor und Zukunft der deutschen Wirtschaft: Erfolgskonzepte für Management, Finanzierung und Organisation. Springer Fachmedien Wiesbaden, Wiesbaden, pp 351-358. https://doi.org/10.1007/9783-658-09049-4_27

Prahalad CK, Hamel G (1997) The core competence of the corporation. In: Strategische Unternehmungsplanung/Strategische Unternehmungsführung. Physica, Heidelberg, pp 969-987

Raisch S et al (2008) Organizational ambidexterity: antecedents, outcomes, and moderators. J Manag 34(3):375-409
Ridder H (2017) The theory contribution of case study research designs. Bus Res 10(2):281-305. https://doi.org/10.1007/s4068 5-017-0045-Z

Schaupensteiner N, Weiß L (2018) How to derive projects from megatrends Strategy Development and Scenario Technique. Retrieved April 7, 2020. https://de.slideshare.net/MHPInsights/strategiee ntwicklung-und-szenariotechnik. Accesed 21 Nov 2019

Schwaber K, Beedle M (2002) Agile software development with Scrum, vol 1. Prentice Hall, Upper Saddle River

Sinek S (2009) Start with why: How great leaders inspire everyone to take action. Penguin, London

Stake RE (1995) The art of case study research. Sage, Thousand Oaks Statistisches Bundesamt (2019) Anteile Kleiner und mittlerer Unternhehmen an ausgewählten Merkmalen 2017 nach Größenklassen in \%. Retrieved Oktober 22, 2019. https://www.destatis.de/DE/ Themen/Branchen-Unternehmen/Unternehmen/Kleine-Unter nehmen-Mittlere-Unternehmen/Tabellen/wirtschaftsabschnitt e-insgesamt.html?nn=208440\#fussnote-1-130538. Accesed 21 Nov 2019

Stickel-Wolf C et al (2005) Wissenschaftliches Arbeiten: Erfolgreich studie-ren-gewusst wie!, 3. Auflage, Wiesbaden

Tushman ML et al (1996) Ambidextrous organizations: managing evolutionary and revolutionary change. Calif Manag Rev 38(4):8-29. https://doi.org/10.2307/41165852

Yin RK (2003) Case study research design and methods, 3rd edn. Applied social research methods series 5

Zukunftsinstitut. Retrieved August 2, 2019. https://www.zukunftsin stitut.de/index.php?id=1532. Accesed 21 Nov 2019 